\title{
The Historiography of the Twentieth-Century Classical Performer: Life, Work, Artistry
}

\author{
ADAM BEHAN
}

\begin{abstract}
One dominant issue in the writing of music histories is the question of how (or indeed whether) a musician's life and work can be interwoven convincingly. In recent years, music biographers have begun to reassess the historical legacies of many significant musicians with this issue in mind, but their critical reflections have for the most part focused on composers. This article seeks to transfer some of this rethinking - particularly on the life/work question - to the twentieth-century classical performer. Doing so reveals a historiography of the performer which sharply divides life and work in a way that is disciplinarily entrenched between biographical approaches on the one hand and empirical approaches to recordings on the other. After illustrating the nature and development of this division, I conclude by calling for greater scholarly convergence and suggest two directions forward, taking leads from artistic research and popular music studies in doing so.
\end{abstract}

'Musical biography', write Christopher Wiley and Paul Watt, 'has historically held something of a problematized or, to borrow Philip Olleson's words, an "untidy" place within music history.' ${ }^{1}$ Aimed for the most part towards a public rather than specialist readership, it is a genre that has 'long stood outside the musicological arena'. That Wiley and Watt acknowledged this complication in 2019 - thirty-seven years after Maynard Solomon's probing reflection on the musicologically critical position that he felt biography should occupy - is an indication that the biographical genre remains in some ways the black sheep of the music history family. ${ }^{2}$

Emerging as it did in 1982, Solomon's article came at a time of radical change in musicology that saw a seismic shift in emphasis towards musical context - essentially, towards what are often dubbed 'extra-musical' factors - and away from positivism. ${ }^{3}$ Targeting the 'analogy of artistic to divine creation' and the notion that 'the artist is a more or less passive medium through whom speaks some incarnation of an ideal', Solomon's argument was not so much that prior biographical knowledge of musicians is essential to understand their music, but rather that we 'approach every work of art with a more or less extensive set of preliminary assumptions':

Email: aojb2@cam.ac.uk

1 Christopher Wiley and Paul Watt, 'Musical Biography in the Musicological Arena', Journal of Musicological Research 38/3-4 (2019), 187.

2 Maynard Solomon, 'Thoughts on Biography', 19th-Century Music 5/3 (1982).

3 Three years later, Joseph Kerman would publish Musicology and unfold a much wider critique of positivism in musicology. See Joseph Kerman, Musicology (London: Fontana Press/Collins, 1985). 
162 Behan The Historiography of the Twentieth-Century Classical Performer: Life, Work, Artistry

there is no such thing as an unconditioned apprehension of an artwork ... We hear every musical composition as a member of its genre, as one segment of the oeuvre of its composer, as a product of its historical period, as symbolic action whose meanings are filtered through the judgements of prior generations-and as an emanation of the (presumed) personality of its composer. ${ }^{4}$

Instead of seeing this as in some way threatening to or distracting from the musical 'ideal', Solomon's point was that this kind of knowledge should be explicitly considered valuable to our aesthetic and scholarly discourses.

The fingerprints of the 'new' musicology are evident in Solomon's work, and a certain amount of historical distance has since put the issues at stake into much clearer relief. Jolanta T. Pekacz's diagnosis is that the 'assumption of the autonomy and self-referentiality of music implied that musical works must be approached and understood through the analysis of their inner structures, exclusive of extra musical factors', and that this 'effectively relegated the genre of biography to the margins of the discipline of musicology' ${ }^{5}$ One task for more recent musical biographers has centred on revisiting the very foundations of the biographical traditions that we have inherited, which - as Wiley points out - owe much to the 'hagiographical climate of the later nineteenth-century'. ${ }^{6}$ A larger issue which has re-emerged, however, one with all kinds of musicological implications, is 'the difficulty of incorporating such biographical knowledge into music analysis and criticism'. Indeed, Solomon has suggested that 'the primary area of dispute about the value of biography appears to centre on the vexed question of how - or whether - the pathways between life and art can be mapped, whether a "personal" factor in creativity can be identified'. ${ }^{8}$ How, in other words, are we to interrelate a musician's life and work convincingly?

This article attempts not so much to answer this question as to bring it to bear on the treatment of the classical performer as a historical subject in musicology. Transferring these historiographical perspectives to the literature on twentieth-century classical performers reveals a musicological domain that compartmentalizes the lives and work of performers quite considerably. Before the emergence of performance studies as a field of musical inquiry in its own right, the detailed study of individual performers was for the most part restricted to the genre of popular biography, one which is rich in contextualization but light on rigorous engagement

4 Solomon, 'Thoughts on Biography', 275.

5 Jolanta T. Pekacz, 'Introduction', in Musical Biography: Towards New Paradigms, ed. Jolanta T. Pekacz (Aldershot: Ashgate, 2006), 3.

6 Christopher Wiley, 'Biography and Life-Writing', in The Oxford Handbook of Music and Intellectual Culture in the Nineteenth Century, ed. Paul Watt, Sarah Collins, and Michael Allis (Oxford: Oxford University Press, 2020).

7 Jolanta T. Pekacz, 'Musical Biography - Further Thoughts', Music's Intellectual History: Founders, Followers \& Fads, ed. Zdravko Blažeković and Barbara Dobbs MacKenzie (New York: RILM, 2009), 846. Pekacz similarly notes that 'our present-day perception of the lives of prominent composers and performers of the past has been largely formed by cultural and political assumptions of nineteenth-century biographers and their twentieth-century followers'. See Pekacz, 'Introduction', Musical Biography, 5.

8 Maynard Solomon, 'Biography', in The New Grove Dictionary of Music and Musicians, 2nd edn, ed. Stanley Sadie and John Tyrrell (London: Macmillan, 2001). Version at Grove Music Online, ed. Laura Macy (www.oxfordmusiconline. com/grovemusic/view/10.1093/gmo/9781561592630.001.0001/omo-9781561592630-e-0000041156?rskey=0AYRHt). 
with the performer's ability as it is captured, for instance, in recordings. With the rise of performance studies, the use of empirical methods to quantify and discuss what is termed performer 'style' has become prevalent, but often without any attempt to embed that style within the context of said performer's life or cultural surroundings. In short, the literature on performers exhibits the kind of sharp divide between life and work that has persistently been questioned by the likes of Solomon, Pekacz, and Wiley. What all this amounts to is a historiographical problem in the writings of histories and biographies of performers, one which is particular to the twentieth century at least in part due to the varying treatment of the special heritage of recordings that we have which documents what and how performers played. In what follows, I demonstrate the entrenchment of this divide. First, I examine the relatively neglected strand of music biography that focuses on performers before assessing the values and alternatives offered by empirical approaches to recordings. I conclude by asking how the opposing positions taken in these bodies of literature might usefully be brought together, drawing on perspectives from artistic research and popular music studies in doing so.

\section{The performer in biography}

Nicholas Cook writes that most 'so-called histories of music are really histories of composition, or even compositional innovation'. ${ }^{9} \mathrm{He}$ is most likely speaking of general historical surveys and standard textbooks, the likes of which Daniel Barolsky has observed that performers are 'almost entirely absent' from. ${ }^{10}$ Perhaps unsurprisingly, then, the thrust of the foregoing critical reflections on biography overwhelmingly focuses on composers. Pekacz's book features essays on the biographical legacies of Bach, Handel, Chopin, Ravel, Liszt, Mendelssohn (Fanny rather than Felix), and Verdi; Wiley and Watt's special issue in The Journal of Musicological Research includes several more obscure composers (such as Otakar Ostrčil, Mordecai Seter, and Peadar Kearney) and one performer - the nineteenthcentury tenor Sims Reeves. ${ }^{11}$ That composers have larger reputations, longer legacies, and in most cases much more biographical undergrowth to be worked through is one explanation for this state of affairs. It is also relevant that the evidence of compositional handiwork is documented in ways that musicologists are well-trained, theoretically and analytically, to handle. The fact that what twentieth-century performers do (and, admittedly, only a relatively impoverished amount of it) is captured in sound recordings has created quite significant obstacles for research analogous to the analysis of composers' scores. It is only relatively recently that tools sophisticated enough to allow such analysis have been developed. ${ }^{12}$

Naturally, none of this has stopped biographers writing about performers. Many biographies of this kind exist, are relatively recent, and - if we are to accept Solomon's and

9 Nicholas Cook, Beyond the Score: Music as Performance (Oxford: Oxford University Press, 2013), 3.

10 Daniel Barolsky, 'Performers and Performances as Music History: Moving Away from the Margins', in Norton Guide to Teaching Music History, ed. Matthew C. Balensuela (New York: Norton, 2019), 159.

11 Pekacz, Musical Biography; Christopher Wiley and Paul Watt, eds., 'Musical Biography: Myth, Ideology, and Narrative', Journal of Musicological Research 38/3-4 (2019).

12 Sonic Visualiser - on which more later - is an important example of such a development (see www.sonicvisualiser.org/, accessed 8 June 2020). 
$164 \mid$ Behan The Historiography of the Twentieth-Century Classical Performer: Life, Work, Artistry

Pekacz's reasoning - significantly shape our understandings not only of performers' lives but also of their musical legacies. In that sense, music biography is one of the few areas of musical inquiry to have traditionally taken classical performers seriously, and examples can be found that examine the vast majority of the twentieth century's most well-known conductors and instrumentalists. To keep things manageable, I focus here on monographs of solo pianists, not only because this strand of performer biography is particularly well represented but also because its traits and characteristics are typical of the biographical literature more generally.

What is interesting about many of the earlier biographies under consideration here is that the 'problem' of discussing the performer's output and life appears not to have been much of a problem at all. Often, they were simply shunted into different chapters or sections. Harvey Sachs, in his biography of Arthur Rubinstein, makes the case that ' $\mathrm{h}$ ] ealthiness and generosity were the quintessential qualities of his music-making, and these qualities did not exist in a void: they were a manifestation of elements in his character, which was much richer and more complicated than his memoirs revealed'. That his explicit research aim was 'to compare Arthur Rubinstein's official self-portrait with the unofficial portrait that his papers, the people close to him, and outside observers have created, cumulatively' suggests a study which is more life-focused than anything else. ${ }^{13}$ So it is not surprising that it features two sections, 'Part I: The Life' and 'Part II: The Recorded Legacy'. It is in Part II that Sachs deals with the recordings in what he admits is a 'highly personal' survey, one which moves broadly chronologically, by composer, and in a manner typical of music criticism. ${ }^{14}$ Harold C. Schonberg offers the reader of his monograph of Vladimir Horowitz not one but four appendices detailing the Russian pianist's recordings, arranged chronologically (Appendix I: 1926-53; Appendix II: LP and Stereo; Appendix III 1965-82; and Appendix IV: 1985-89), a kind of history within a history. ${ }^{15}$ It is unquestionably relevant that these authors were often prominent music critics who had spent long hours listening to and reviewing recordings of classical music.

That there is something potentially more problematic to be teased out in this 'appendicization' of performance is revealed in Jeremy Nicholas's biography of Leopold Godowsky. Nicholas notes that 'it has been my prime aim in writing this story of Godowsky's life to excite the interest of pianists, piano-lovers, music promoters and publishers into re-examining his legacy for themselves'. ${ }^{16}$ Godowsky was known as a composer as well as a pianist, and in fact Nicholas is speaking of Godowsky's compositional legacy here rather than his performances. Yet while Nicholas is careful to acknowledge that he has purposefully avoided engaging with Godowsky's compositions - 'this book contains no musical illustrations and no critical study or analysis of Godowsky's music' - on the basis that it would have required 'a further book in itself and 'would have inevitably led to a subjective view of a personal selection', no analogous obstacle prevented him from discussing Godowsky's recordings in detail in a separate

13 Harvey Sachs, Arthur Rubinstein: A Life (London: Weidenfeld \& Nicolson, 1996), x.

14 Sachs, Arthur Rubinstein, 411.

15 Harold Schonberg, Horowitz: His Life and Music (New York: Simon \& Schuster, 1992).

16 Jeremy Nicholas, Godowsky, The Pianists' Pianist: A Biography of Leopold Godowsky (Hexham: Appian Publications \& Recordings, 1989), xxiv. 
appendix, just like Sachs and Schonberg. ${ }^{17}$ This might seem relatively innocuous, but there is an implicit valuing not only of compositions over performances, but also of the respective relevance of a musician's life to their performances in comparison to their compositions.

Sachs, Schonberg, and Nicholas all substitute their historian hats for their reviewer ones in these discographical postludes, and in doing so they move away from painstaking historical construction of their subjects' lives and adopt a more flexible and reflective tone that allows them to exercise a different kind of musical expertise. On the face of it, then, there is a tendency to distinguish quite rigidly between biography and recordings in a way that manifests itself stylistically as well as structurally. In practice, such a clean distinction between historical writing and music criticism does not exist - Cook, for one, has shown just how blurry this boundary is with respect to the critical reception of Beethoven's Wellington's Victory, Op. 91 - but the apparent enactment of such a distinction is a feature of early biographical writing. ${ }^{18}$ The important point in this respect concerns the implicit value attributed to recordings as a type of historical document: it is significant that recordings are treated quite differently to the many other historical sources (e.g., letters, diaries, reminiscences, memoirs) that are routinely drawn upon in the writing of biography.

Of course, the late 1980s and early 1990s were years when recordings were generally not taken very seriously as objects of historical or analytical scrutiny by traditional musicologists, and with that in mind it is not so much the work of these authors that I wish to critique as it is the biographical tradition of which they form an important early part. ${ }^{19}$ My point here - my first main point in this section - is that, if nothing else, this kind of partitionist approach demonstrates the marginalization of what I would call the work of the performer, or more specifically, the documents we have that record their work. The treatment of recordings as review material rather than as the basis of serious historical evaluation says something about the value that recordings are deemed to have and diminishes the profile of the performer in question. I mentioned that the more advanced tools for analysing and comparing recordings that are available today did not exist at this stage, but it is also the case that this question of separation is a methodological problem that remains unresolved. There is a lingering feeling, for instance, that something quite major is missing from Stephen Lehmann and Marion Faber's study of Rudolf Serkin when they reveal that their seemingly exhaustive list of primary sources 'Serkin's correspondence (from his own papers and numerous other archival collections), unpublished accounts by relatives, programs, reviews, and memoirs of associates' - does not include recordings. This is the case despite the authors' position that 'the essential core of Serkin's life was music, and it is in his music making that his life's deepest truths are expressed'. ${ }^{20}$

17 Nicholas, Godowsky, xxiii.

18 Nicholas Cook, 'The Other Beethoven: Heroism, the Canon, and the Works of 1813-14', 19th-Century Music 27/1 (2003).

19 Two important early milestones for performance studies were reached in the early 1990s, however. See John Rink, 'Review of Musical Structure and Performance by Wallace Berry', Music Analysis 9/3 (1990), and Robert Philip, Early Recordings and Musical Style: Changing Tastes in Instrumental Performance, 1900-1950 (Cambridge: Cambridge University Press, 1992).

20 Stephen Lehmann and Marion Faber, Rudolf Serkin: A Life (Oxford: Oxford University Press, 2003), 5-7. As in the earlier biographies by Sachs, Schonberg, and Nicholas, Serkin's recordings make an appearance in the book's 
166 Behan The Historiography of the Twentieth-Century Classical Performer: Life, Work, Artistry

Faced with the complicated prospect of dealing with familiar types of sources that they were very capable of handling on the one hand, and another kind (recordings) for which no equivalent methods existed on the other, other biographers have often opted to omit the latter. In the introduction to her biography of Dame Myra Hess from 1976, Marian C. McKenna humbly acknowledges that the purpose of her book is 'purely historical':

It is the result of my training as an historian and of my life-long appreciation of music. Future writers interested in the Hess phenomenon may attempt more in the way of explanation and assessment of her art. I can assist them only by presenting facts which hitherto have not been generally known, and by providing what will, I hope, be a clear and truthful account of the character and personal development of one of the most beloved artists of the twentieth century. ${ }^{21}$

McKenna's use of the word 'art' is crucial here. It is left purposefully ambiguous, but we can assume that the kind of assessment she suggests would at least partly involve recollections or recordings of Hess's playing. Though not always acknowledged so explicitly, this principle more or less underpins most biographical studies of performers to this day. This leads to my second main point for this section, which is that just as the study of a performer's art without proper consideration of their work seems incomplete, so too would a study of a performer's art that entirely omitted their subject's life. Seen in this light, McKenna's biography becomes not just an account of Hess's life, but also a crucial part of the story of her artistry. When McKenna illustrates the emergence of the National Gallery Concerts in London during the Second World War - which Hess not only performed consistently at between 1939 and 1946 but also founded - and argues, for instance, that the 'successive performances Myra gave of Beethoven's "Appassionata" Sonata were, in a sense, acts of defiance against the forces of evil unleashed in the world', she is inadvertently making a case for the importance of 'extramusical' contexts. ${ }^{22}$ The same belief underlies Stuart Isacoff's account of the Texan pianist Van Cliburn's spectacular triumph at the First International Tchaikovsky Piano Competition in 1958 in the throes of ratcheting Cold War tension. Isacoff describes 'Van's art' as representing 'the face of freedom' for many in the audience: '[p]erforming under the auspices of a repressive regime and before an intimidating jury of some of the world's greatest musicians, he seemed to answer to no authority other than the shifting tides of his own soul. The mere act of hearing him became liberating. ${ }^{23}$

If Hess's wartime heroics - what McKenna calls 'Myra's musical patriotism' - and Van Cliburn's moment of international stardom seem like exceptional examples, that is only because of the historical significance of the performances in question. The point stands on a personal level, too. The importance of the year 1973 in the career and deteriorating mental

appendices. The book also includes an accompanying CD which is unreferenced in the main text, something which is perhaps a manifestation of the biography/recordings divide peculiar to the noughties.

21 Marian C. McKenna, Myra Hess: A Portrait (London: Hamilton, 1976), xi.

22 McKenna, Myra Hess, 164.

23 Stuart Isacoff, When the World Stopped to Listen: Van Cliburn's Cold War Triumph, and its Aftermath (New York: Knopf, 2017), 8. 
health of John Ogdon is one such case: in a Belfast hotel after a performance with the Ulster Orchestra, he carved crosses onto his temples and cut his hands, something which Charles Beauclerk speculates could have 'reflected John's growing sense that he was destined to bear the cross of his father's madness'. ${ }^{24}$ Once known, it seems impossible to separate these giant cut hands, the ones he used in earth-shattering performances of Kaikhosru Sorabji's Opus clavicembalisticum, from those same hands he used to physically assault his wife, Brenda. ${ }^{25}$ At the very least, that he then suffered a mental breakdown, was eventually diagnosed with 'a bipolar disorder that was paranoid and psychotic in nature', and spent time in several psychiatric hospitals while his already troubled marriage began to disintegrate further implies that we cannot treat his performances in the last fifteen years of his life in the same way as those, say, from his early career. ${ }^{26}$ Even in the case of more specifically musical beliefs that might not seem particularly distinct, there is much to learn. For example, Rudolf Serkin's commitment to Werktreue and the composer's intentions - his dogged 'determination to track down the original version to get at the composer's intent, before and beyond the interpretations and distortions made by any editor, even the most revered' - can also tell us something about what his performing style meant to him, and what he imagined he was doing when he worked through a score. ${ }^{27}$ It is not so much about uniqueness (i.e., that each performer's context engendered a distinct performing style) as it is about meaning, either personal or more broadly cultural.

Glenn Gould is often if not always the first name that comes to mind in any discussion of twentieth-century pianists that concerns performing style. Though Gould has been the subject of several biographies, Kevin Bazzana noted in 1997 that only one German book had attempted at that stage to deal with Gould's playing in any purposeful way, the rest falling safely into the biographical category. ${ }^{28}$ His book, Glenn Gould: The Performer in the Work, pursues what Bazzana calls the 'Gould aesthetic', and his attempt to dovetail Gould's playing with his performing ideology sets it apart from the other biographical efforts I have considered: he writes that Gould's 'aesthetic premisses are sometimes stated, more often strongly implied, in his writings and interviews, but can be inferred most reliably from his musical practices'. 29 In pinpointing Gould's musical idealism (including his internalist obsession with formal properties and structures, and his relative indifference to historical context) and placing him in a tradition of Schoenbergian thinking, Bazzana outlines a philosophy of music that was not abstract, but in fact had direct implications for what and how Gould performed. This philosophy revolved around the contrapuntally idealist Bach and shaped a performing style which (as Bazzana shows) was chiefly characterized by a geometrical

24 Charles Beauclerk, Piano Man: A Life of John Ogdon (London: Simon \& Schuster, 2014), 225.

25 Beauclerk, John Ogdon, 370.

26 Beauclerk, John Ogdon, 227, 289.

27 Lehmann and Faber, Rudolf Serkin, 137.

28 Kevin Bazzana, Glenn Gould: The Performer in the Work (Oxford: Clarendon Press, 1997), viii; Bazzana himself would make his own more firmly biographical contribution to Gould literature some years later. See Kevin Bazzana, Wondrous Strange: The Life and Art of Glenn Gould (New Haven, CT: Yale University Press, 2003). 
168 Behan The Historiography of the Twentieth-Century Classical Performer: Life, Work, Artistry

approach to rhythm, a commitment to proportional tempos, and a preference for terraced dynamics and a non-legato style. ${ }^{30}$ It is largely Gould's sense of personal conviction in his 'bridging of his theories and his practices' to which Bazzana attributes his success:

In his best performances, even where highly idiosyncratic, there is a real sense of unity between idea and practice, between thought and sound. The extreme tempos, the upside-down textures, the absurd ornaments-Gould could make such eccentricities sound convincing in performance because he was convinced by them, because they were such honest reflections of his aesthetic ideas, and also, of course, because he had the keyboard technique to render them in an engaging manner. ${ }^{31}$

What is particularly attractive about this observation is that it does not rely on the idiosyncrasy of Gould's style as the ultimate arbiter of his pianism. Rather, the significance lies at least in part in the conviction that he had in his own playing and how this related to his wider aesthetic thinking - that his performances were 'not just readings of pieces of music but documents of his world view. ${ }^{32}$

Another way of putting it is to speak of a performer's 'subjectivity'. This is what Maria Razumovskaya does with Heinrich Neuhaus, arguing that his subjectivity 'pervaded everything he did in a way that becomes integral to understanding him both as a person and an artist'; thus she commits herself to uncovering 'how Neuhaus's personal circumstances may have translated into his artistic decisions and tastes'. ${ }^{33}$ In one incident, Neuhaus urged his pupil Anatoly Vedernikov to sense the 'image of cypresses' in Bach's Prelude and Fugue in E flat minor from the first book of the Well-Tempered Clavier, a request to which an exasperated Vedernikov responded by storming out. ${ }^{34}$ For Vedernikov, it was the needless romanticization of Bach's music that provoked his outrage. But Razumovskaya shows this particular image to be grounded firmly in Neuhaus's own life experience, namely his discovery of the piece during his youth while steeped in the writings of Friedrich Nietzsche and living in Italy. Italy was a 'spiritual home' for Neuhaus, of which he recalled associating 'the austere and straight cypress trees' with the 'magisterial stillness of the Italian cemetery'. His cypresses are an example in miniature of Neuhaus's larger idea of 'autopsychography' - the notion that every 'autobiographic occurrence that has left its distinct mark on the interpreter's soul . . . is a possible ingredient' for artistic practice. A simpler way of putting this is to assert that 'art only becomes great if it contains direct traces of the artist's life experiences'. ${ }^{35}$ This was, at least for Neuhaus, 'the difference between a "pianist" and an "artist".

This neatly leads back to the life/work question, but without resolving it. Razumovskaya rules out referring to Neuhaus's recordings on the basis that they capture only a physically

30 Bazzana, The Performer in the Work, 259.

31 Bazzana, The Performer in the Work, 257.

32 Bazzana, Wondrous Strange, 12.

33 Maria Razumovskaya, Heinrich Neuhaus: A Life Beyond Music (La Vergne: Boydell \& Brewer, 2018), 10.

34 Razumovskaya, Heinrich Neuhaus, 11-14.

35 Razumovskaya, Heinrich Neuhaus, 13-14. 
weakening Neuhaus who himself asked for them to be destroyed. ${ }^{36}$ Bazzana's study does engage with Gould's recordings, and while his study came at a stage when theoretical and systematic approaches to studying recordings were in their infancy, his direct engagement with Gould's performing style seems to be the exception that proves the rule (and, in that sense, a very valuable precedent). ${ }^{37}$ Razumovskaya's navigation around Neuhaus's recordings though insightful as an account of its subject - seems like a missed opportunity of sorts. ${ }^{38}$ Part of this comes down to protectivity: Razumovskaya avoids Neuhaus's recordings in much the same way as Nicholas apologizes for Godowsky's, which he assures 'only rarely betray evidence of the superhuman powers with which his contemporaries credited him.' ${ }^{\text {, }}$ Even in cases where it is unidirectional, the relationship between writer and subject fosters a special intimacy, and it is no revelation that biographers usually seek to portray their musicians in a light that is life-affirming. But there is also a sense in which scholars protect themselves by avoiding the (admittedly complicated) methodological issues tangled up in incorporating recordings more fully into biographical work.

Nevertheless, that this division persists is only the smaller point that I have tried to make in this discussion. I hope first and foremost to have demonstrated the relevance of life, context and the 'extra-musical' to the study of performers and specifically how these things have the potential to shape the meaning of the music they make. The argument in favour of contextually grounded research in musicology is not new, but that there is a case here that needs to be reiterated - thirty-eight years after Solomon made it in relation to biography - is of particular relevance to the discussion of the performer's work that follows.

\section{The performer in empirical approaches to recordings}

The missing piece of the biographical puzzles - musical recordings, the traces of performers in action - has, separately from the literature on pianists that I have just surveyed, become a mainstream area of musicological research in the past three decades. The emergence of performance studies as a subfield within musicology since that time reached an important landmark with the establishment of the AHRC Research Centre for the History and Analysis of Recorded Music (CHARM) in 2004, and during this centre's five-year lifespan a huge amount of work was put into developing methodological and theoretical approaches to recordings which continue to inform the way in which musicologists handle them to the present day. ${ }^{40}$ Perhaps what characterized CHARM more than anything else was the adoption and advocacy by its directors of the computer program Sonic Visualiser. This software, developed at Queen Mary, University of London, allows for the extraction of empirical data from recordings that can then be scrutinized and enlisted for musicological ends. As Cook (who directed

36 Razumovskaya, Heinrich Neuhaus, 16-17.

37 Bazzana, The Work in the Performer, xiv.

38 Neuhaus's dissatisfaction with his own recordings by no means renders them of no value to an understanding of his pianism; he was not the first nor the last musician not to like what he heard when his recordings were played back to him.

39 Nicholas, Godowsky, xvi.

40 See the CHARM website (https://charm.rhul.ac.uk/about/about.html, accessed 12 June 2020). 
170 Behan The Historiography of the Twentieth-Century Classical Performer: Life, Work, Artistry

CHARM) has written, Sonic Visualiser provides 'a working environment for studying recordings that replicates much of the functionality we take for granted in conventional music analysis, where you flick backwards and forwards to compare passages in a score, or compare parallel passages in different scores'. ${ }^{41}$ All of this meant that musicologists now had the resources to discuss the details of performers' playing in a tangible way - exactly what biographers of performers had traditionally lacked.

These details, including such parameters as tempo, dynamics, timbre, and articulation, have been broadly conceptualized as the essential components of performance style, and many examples of performance studies based their investigations around them (for instance, Cook's project on the evolution of phrase-arching, and John Rink, Neta Spiro, and Nicolas Gold's study of 'performance motives', both taking Chopin mazurkas as case studies). ${ }^{42}$ But it is Daniel Leech-Wilkinson who has given the most sustained attention to the issue of performance style, which he describes as being 'very like composition style' and operating on 'a number of different levels'. All performers, he writes, 'have a slightly different collection of habits, which we can call their "personal style", and personal styles can be contextualized more broadly within period styles, national styles, and other potential groupings. ${ }^{43}$ With respect to writing wider histories of performing styles, his suggestion is to take a bottom-up approach. He argues that to 'make progress we really need now to undertake many detailed studies of local and especially of personal styles, and only then, using that detail as a secure base, will we be able to build up new and better pictures of general period or national style'. ${ }^{4}$

Leech-Wilkinson elaborated on this in his 2009 monograph on musical performance, in which he modelled performance style in terms of 'expressive gestures'. He defined an expressive gesture as 'an irregularity in one or more of the principal acoustic dimensions (pitch, amplitude, duration), introduced in order to give emphasis to a note or chord-usually the start of a note or chord', essentially involving 'sounding notes for longer or shorter, or louder or softer, or in some other way different compared to the local average'. ${ }^{45}$ A performance style, in turn, 'is a set of expressive gestures characteristic of an individual performer that taken together constitute their "personal style"; or a set characteristic of a period ("period style"), or a group (for example, national style)'. ${ }^{46}$ Leech-Wilkinson provided a prototypical example of what he means in a later article on the personal style of German singer Elena

41 Cook, Beyond the Score, 145-6.

42 Cook, Beyond the Score, 176-223; John Rink, Neta Spiro, and Nicolas Gold, 'Motive, Gesture and the Analysis of Performance', in New Perspectives on Music and Gesture, ed. Anthony Gritten and Elaine King (Farnham: Ashgate, 2011).

43 Daniel Leech-Wilkinson, 'Recordings and Histories of Performance Style', in The Cambridge Companion to Recorded Music, ed. Nicholas Cook, Eric Clarke, Daniel Leech-Wilkinson, and John Rink (Cambridge: Cambridge University Press, 2009), 248.

44 Leech-Wilkinson, 'Recordings and Histories of Performance Style', 254.

45 Daniel Leech-Wilkinson, The Changing Sound of Music: Approaches to Studying Recorded Musical Performances (London: CHARM, 2009), ch. 8 par. 15 (https://charm.rhul.ac.uk/studies/chapters/chap8.html\#par15).

46 Leech-Wilkinson, The Changing Sound of Music, ch. 8 par. 18 (https://charm.rhul.ac.uk/studies/chapters/chap8. html\#par18). 
Gerhardt (1883-1961) in which he explored her gestures in the realm of timbre, vibrato, scoops, portamento, tuning, and rubato. ${ }^{47}$

All this is somewhat subsidiary, however, to Leech-Wilkinson's basic point - the thread that runs through his many CHARM-era publications - which is that performing style changes quite radically (if slowly) over time and that this has implications both for the historical performance movement and for any attempt to study musical meaning through scores alone. ${ }^{48}$ Musical meaning is exactly what Leech-Wilkinson has in his sights in an earlier article on recordings of Schubert's lied setting of 'Die junge Nonne', in which he tries 'to show how different performances and different performance styles facilitate the emergence of particular meanings'. ${ }^{49}$ On the basis of the text and Schubert's piano accompaniment, he identifies 'at least three possibilities for a singer': that the girl in question 'may genuinely be excited about entering the convent'; that she 'may be disturbed by sexual emotion confused with her approaching "marriage" to God'; and that she 'may be delirious and close to death'.

Of course, we cannot hear early recordings with early ears, and specifying meaning exactly in these circumstances is very difficult: ' $\mathrm{t}$ ] ranslating across the decades is very hard without a great deal of contextualisation,' Leech-Wilkinson writes, 'the research basis for which does not yet exist. Without it we can speak with confidence only of modern responses. ${ }^{51}$ Returning to the model of expressive gestures, Leech-Wilkinson invokes this caveat too:

the precise signification of an expressive gesture must depend on its context to a very significant degree, and this is another reason to be wary of any kind of dictionary of performance gestures that seeks to fix meanings: it is essential to be sensitive to the local and period context in assigning any kind of meaning to a gesture, and to localise that meaning within a particular performance. ${ }^{52}$

This is presumably what he meant when he said of his work on Gerhardt that his aim was 'not so much understanding as simply observation and characterisation of style' - in other words, that this was the preliminary work that would perhaps underpin a more culturally contextualized approach. ${ }^{53}$ Indeed, his study of Alfred Cortot (1877-1962) points towards this: the conclusion he reaches with Cortot's unexpectedly hyper-controlled interpretative approach is that this makes perfect sense 'when we think of the other Cortot, not the dreamy pianist we encounter in his books and on film, but rather the highly competent administrator, the founder and director of the École Normale de Musique, the Vichy minister managing

47 Daniel Leech-Wilkinson, 'Performance Style in Elena Gerhardt's Schubert Song Recordings', Musicae Scientiae 14/2 (2010).

48 Leech-Wilkinson, 'Recordings and Histories of Performance Style', 247-8.

49 Daniel Leech-Wilkinson, 'Sound and Meaning in Recordings of Schubert's "Die Junge Nonne"', Musicae Scientiae 11/ 2 (2007), 210.

50 Leech-Wilkinson, 'Sound and Meaning in Recordings of Schubert's “Die Junge Nonne”, 212.

51 Leech-Wilkinson, 'Sound and Meaning in Recordings of Schubert's "Die Junge Nonne", 225.

52 Leech-Wilkinson, The Changing Sound of Music, ch. 8 par. 18 (https://charm.rhul.ac.uk/studies/chapters/chap8. html\#par18).

53 Leech Wilkinson, 'Performance Style in Elena Gerhardt's Schubert Song Recordings', 59. 
172 Behan The Historiography of the Twentieth-Century Classical Performer: Life, Work, Artistry

professional musical life in wartime France. ${ }^{54}$ The big question here is what exactly context means in understanding performance style, and this is something I will come back to.

I have given so much attention to Leech-Wilkinson's research because his theorization of performance style and broader use of empirical approaches to recordings have significantly influenced subsequent studies of recorded performances. ${ }^{55}$ When Leech-Wilkinson says that, conceptually, 'performance style is very like composition style', he is laying the foundations for future work by pointing to two obviously significant elements of musical practice that have received staggeringly different levels of scholarly attention. ${ }^{56}$ Unsurprisingly, then, several musicologists have taken up the mantra to do for performers what has long been done for composers. For example, Dorottya Fabian and Eitan Ornoy complain that analytical musicologists 'have methods to explain the characteristic features of compositions', but that 'there is precious little beyond the journalistic that attempts to explain the uniqueness of performances and performers'. They argue that '[i]f performance is as significant as the notated work and performers have played a decisive role in the reception and canonization of pieces, musicologists must be able to show what identifies a particularly famous interpreter just as they can state what characterizes the works of a prominent composer'. ${ }^{57}$

Fabian believes that if we wish to be 'serious about putting the performer centre stage and claiming for her or him a pivotal role in the identity and reception of western classical compositions ... we must undertake the painstaking data gathering and analytical tasks that were typically applied to written texts/scores until the $1980 \mathrm{~s}^{, 58}{ }^{58}$ Dario Sarlo, too, proposes that we should investigate individual performer styles much in the way musical analysts such as Heinrich Schenker, Donald Tovey, and countless others study the styles and output of prominent historical composers'. 59 'Why', Sarlo writes, 'should we not place Toscanini, Heifetz, and Gould on the same elevated platform as Beethoven, Mozart, and Bach?'60

There is an understandable grievance here - the cultural significance long attributed to composers has gone side-by-side with analytical investigation into their compositions but there are also problems. The first is whether or not the business of canon formation should be a priority or even desirable for performance studies. The second is that there is

54 Daniel Leech-Wilkinson, 'Making Music with Alfred Cortot: Ontology, Data, Analysis', in Gemessene Interpretation Computergestützte Aufführungsanalyse im Kreuzverhör der Disziplinen, ed. Heinz Loesch and Stefan Weinzierl (Mainz: Schott, 2011), 138.

55 In their edited volume, Dorottya Fabian, Renee Timmers, and Emery Schubert largely base their model of musical expressiveness on Leech-Wilkinson's 'appealing' definition of expressive gestures, and it is this model which they suggested to the contributing authors as a working definition. See Fabian, Timmers, and Schubert, 'Introduction', in Expressiveness in Music Performance: Empirical Approaches across Styles and Cultures, ed. Dorottya Fabian, Renee Timmers, and Emery Schubert (Oxford: Oxford University Press, 2014), xxi-xxiv.

56 Leech-Wilkinson, 'Recordings and Histories of Performance Style', 248.

57 Dorottya Fabian and Eitan Ornoy, 'Identity in Violin Playing on Records: Interpretation Profiles in Recordings of Solo Bach by Early Twentieth-Century Violinists', Performance Practice Review 14/1 (2009), 2.

58 Dorottya Fabian, A Musicology of Performance: Theory and Method Based on Bach's Solos for Violin (Cambridge: Open Book Publishers, 2015), 16-17.

59 Dario Sarlo, The Performance Style of Jascha Heifetz (Farnham: Ashgate, 2015), 1.

60 Sarlo, Jascha Heifetz, 1. 
quite a lot packed into Fabian and Ornoy's use of the word 'journalistic', and we can only assume that the biographical literature on performers - often, as we have seen, penned by writers who were also music critics - is encompassed in what they are talking about (they cite Bazzana's study of Gould as an exception). Their frustration with the inability of these kinds of biographical approaches to engage rigorously with recordings in fact goes somewhat further in its disavowal of biography, with wide-ranging implications for the relevance of context to empirical approaches.

In an important volume on musical expression in 2014, Fabian, Renee Timmers, and Emery Schubert used the term 'expressiveness' to refer to 'the effect of auditory parameters of music performance'; in other words, expression is defined in terms of music's sound. ${ }^{61}$ This leaves a question mark over where the non-auditory parameters of performance come into play, including not only other forms of sensory input but also the knowledge and assumptions brought to any given performance context - the kind that Solomon spoke of. Cook obliquely references this in the opening of his contribution to the volume, in which he writes that the "term "express" and its multiple derivatives have a peculiarly checkered history in the study of music'. In doing so, he cites Eduard Hanslick's claim that 'aesthetics should be centered on the purely musical' and the implications that this has since had for the "distinction between the "musical" and the "extra-musical" that has remained embedded within musicology to this day. ${ }^{62}$ Here Cook is writing specifically about scores, but the point equally applies to the study of performances. Mine Doğantan-Dack demonstrates this when referencing the 'touching image of the octogenarian American pianist Charles Rosen (1927-2012), who "tottered on stage with the help of a walking stick" towards the grand piano to play his last London concert on 15 May 2011 '. She then asks, 'was this not part of the singular expressiveness that audiences heard in the sounds of his performance?' ${ }^{63}$

Getting away from a hard distinction between the musical and the extra-musical has been one of Cook's central messages in his formulation of music as performance, maintaining that in the 'absence of firm contextualization, the grounding of data in experience, empirical approaches all too easily lose purchase on the issues of social and cultural meaning that form the core focus of musicology'. ${ }^{64}$ He goes so far as to suggest that 'the concept of the extramusical is simply inapplicable to performance'. ${ }^{65}$ Indeed, his most fundamental critique of

61 Fabian, Timmers, and Schubert, 'Introduction', Expressiveness in Music Performance, ed. Fabian, Timmers, and Schubert, xxi.

62 Nicholas Cook, 'Implications for Music Studies', in Expressiveness in Music Performance: Empirical Approaches across Styles and Cultures, ed. Dorottya Fabian, Renee Timmers, and Emery Schubert (Oxford: Oxford University Press, 2014), 331.

63 Mine Doğantan-Dack, 'Philosophical Reflections on Expressive Music Performance', in Expressiveness in Music Performance: Empirical Approaches across Styles and Cultures, ed. Dorottya Fabian, Renee Timmers, and Emery Schubert (Oxford: Oxford University Press, 2014), 4.

64 Nicholas Cook, 'Bridging the Unbridgeable? Empirical Musicology and Interdisciplinary Performance Studies', in Taking it to the Bridge: Music as Performance, ed. Richard Pettengill and Nicholas Cook (Ann Arbor: University of Michigan Press, 2013), 84.

65 Cook, 'Bridging the Unbridgeable?', 79. 
174 Behan The Historiography of the Twentieth-Century Classical Performer: Life, Work, Artistry

empirical approaches is that they can give 'a new lease on life to musicological textualism: recordings are taken out of context and analyzed as self-sufficient objects rather than as traces of human actions in specific social and cultural situations'. ${ }^{66}$ Ultimately, however, he is an advocate of these techniques, and all this comes as part of a general reconciliation that Cook tries to achieve between interdisciplinary performance studies - that have been strong in terms of widening the scope of what counts as valuable in a performance event - and empirical approaches that, as he notes, help 'to avoid the danger of critical circularity' and that give definition to descriptive accounts of performance. ${ }^{67}$ The importance of this, as Cook puts it, 'is because, in performance, everything counts' ${ }^{68}$

I reiterate Cook's points here because it is relevant to much of the empirical work on recordings that has been undertaken since he made them in 2013. Another way of putting his fear of a new kind of 'musicological textualism' is to say that empirical approaches risk equating performance with sound and drawing the line there. Leech-Wilkinson never goes this far, but there is an extent to which this kind of interchangeability bubbles under the surface of some of his work:

Recordings show us that music we think we know intimately sounded quite different in the past. When music sounds different it is different, because music's meaning depends to a very important extent on its sound. Even if you sit at home and read an orchestral score ... the sounds you imagine are those made by a modern orchestra playing as orchestras play today. So however you hear it, there's no experiencing music except through the way it's performed: when the performance changes, the music changes. ${ }^{69}$

There is a potential slippage here in the distinction between performance and sound: 'when music sounds different it is different', and 'however you hear it . . . when the performance changes, the music changes'. But the two are collapsed together in Fabian's monograph on performance:

Normative thinking regarding how Beethoven, or Bach, or any other composer's music 'should go' was challenged, eventually leading to Nicholas Cook's call for a re-evaluation of the framing of musicological investigations to be not music as text (scores, compositions), but music as performance. Or how I prefer to think about it: music as sound. ${ }^{70}$

It is unclear whether Fabian thinks of this alternative definition as liberalizing rather than narrowing. To speak of music as sound instead of music as performance is at the very least to sharpen the divide between the 'musical' and the 'extra-musical'. But Fabian's approach goes much further than that: she describes her method as a 'comprehensive approach to the study

66 Cook, 'Bridging the Unbridgeable?', 76.

67 Cook, 'Bridging the Unbridgeable?', 84.

68 Cook, Beyond the Score, 336.

69 Leech-Wilkinson, 'Recordings and Histories of Performance Style', 246.

70 Fabian, A Musicology of Performance, 7. 
of music performance', one which 'starts tapping into the holistic experience'. ${ }^{71}$ To formulate a 'comprehensive' model of studying music along the lines of sound alone is an entirely different proposition: by 'keeping music performance in the aural domain' - as the title of one of her subsections commits to doing - and asserting that 'most ... musical traditions do not use notation but pass on everything purely aurally', Fabian is at once opening up and then immediately closing down the scope for empirical approaches to performance. ${ }^{72}$

One of the justifications that she offers for this position is that 'we need much more detailed empirical data before an evidence-based narrative of the historical-cultural evolution of performance styles can be written' ${ }^{73}$ Yet it is by no means clear that the unrelenting accumulation of recording data is necessary before any kind of meaningful cultural work can be done. With this in mind, it is worth requoting Fabian's call to 'undertake the painstaking data gathering and analytical tasks that were typically applied to written texts/scores until the 1980s', because there is more than a trivial resemblance of these issues with empirical approaches to recordings to the positivistic music historical and theoretical literature that Joseph Kerman took aim at in $1985 .{ }^{74}$ The positivism that Kerman saw led him to quote R. G. Collingwood on German positivistic historiography in the nineteenth century, pointing out how closely the latter's words fitted 'the musical situation seventy-five years later':

Historians set to work to ascertain all the facts they could. The result was a vast increase of detailed historical knowledge based to an unprecedented degree on accurate and critical examination of evidence. This was the age which enriched history by the compilation of vast masses of carefully sifted material, like the calendars of close and patent rolls, the corpus of Latin inscriptions, new editions of historical texts ... But all through this period there was a certain uneasiness about the ultimate purpose of this detailed research. It had been undertaken in obedience to the spirit of positivism according to which the ascertaining of facts was only the first stage of a process whose second stage was the discovery of laws. Thus historians themselves were for the most part quite happy going on ascertaining new facts; the field for discovery was inexhaustible and they asked nothing better than to explore it. But philosophers who understood the positivist programme looked on at this enthusiasm with misgiving. When, they asked, were the historians going to embark on the second stage? ${ }^{75}$

Of analysts, Kerman wrote elsewhere that it was only 'in more recent times [in other words, until the 1980s] that analysts have avoided value judgements and adapted their work to a format of strictly corrigible propositions, mathematical equations, set-theory formulations, and the like-all this, apparently, in an effort to achieve the objective status and hence the

71 Fabian, A Musicology of Performance, 6, 22.

72 Fabian, A Musicology of Performance, 69-71.

73 Fabian, A Musicology of Performance, 14.

74 Fabian, A Musicology of Performance, 16-17.

75 Kerman, Musicology, 43-4. The quotation is originally from R. G. Collingwood, The Idea of History (Oxford: Clarendon Press, 1946), 127. 
176 Behan The Historiography of the Twentieth-Century Classical Performer: Life, Work, Artistry

authority of scientific inquiry'. ${ }^{76}$ Kerman describes this situation as a kind of 'intellectual time warp' - one in which we would appear to find ourselves once more with the at times staggering data sets that empirical musicologists of performance provide. ${ }^{77}$ Edward T. Cone made a similar observation with respect to analysis and performance long ago, arguing that 'there are alternatives to the rapt admiration of bloodless formulas and jejune diagrams to which our lust for structures sometimes leads' ${ }^{78}$ Cook argues that 'the problem with much musicological writing that adopts empirical methods is that it stops where the data stops, rather than using the data as a jumping-off point for the more informal and listening-based critical or historical interpretation that gives musicology its raison d'être'. ${ }^{79}$ No wonder, then, that Rink has noted his own 'reservations about the aims and outcomes of much of the recent performance-analytical work', pointing out that 'some studies in this vein seem more intent on generating data for its own sake rather than using data to reach musically meaningful conclusions'. 80

What this has led to - and this is my culminating point in this section - is a situation where musicologists writing about individual performers have entirely reversed the approaches used by the biographers surveyed in the previous section. Where music biographers have for the most part written about everything to do with the musician in question other than the development and characteristics of their performing style, empirical musicologists are now doing only that. For example, Sarlo's recent monograph on the violinist Jascha Heifetz aims to construct 'a systematic set of criteria for investigating performance, building a comparative framework by which other similar studies may follow. ${ }^{81}$ He writes that '[s] uch studies have the potential to construct an empirical basis for making claims about performance trends over the last century. This will provide a way of gauging what is unique about performers and will help trace the sources of particular styles and approaches.' In other words, the study of a performer's style 'should ultimately identify those "artistic habits" that are unique to them, and which have influenced others, distinguished them from broader trends in performance practice. Mirroring general studies into composition style, [Sarlo's] study will look for broader patterns and trends that belong to particular eras, teachers, regions and cultures. ${ }^{82}$

Once music is defined in terms of sound, it is not too large a step to take to define a performer's individuality in the same way. This is what Danny Zhou (accompanied by Fabian) does:

Research shows that performers often differ from each other in their use of such parameters as tempo ... and other aspects of timing ... dynamic variation . . . timbre ... ornamentation ... articulation ... pitch control ... and many instrument-specific

76 Joseph Kerman, 'How We Got Into Analysis, and How to Get Out', Critical Inquiry 7/2 (1980), 313.

77 Kerman, Musicology, 43.

78 Edward T. Cone, Musical Form and Musical Performance (New York: Norton, 1968), 98.

79 Nicholas Cook, 'The Ghost in the Machine: Towards a Musicology of Recordings', Musicae Scientiae 14/2 (2010), 12.

80 John Rink, 'The (F)utility of Performance Analysis', in Artistic Practice as Research in Music, ed. Mine Doğantan-Dack (Farnham: Ashgate, 2015), 128.

81 Sarlo, Jascha Heifetz, 2.

82 Sarlo, Jascha Heifetz, 3. 
aspects such as violin vibrato and bowing, as well as piano pedaling. . . We refer to performers' distinctive ways of manipulating these parameters as 'performers' individuality,' which research has shown to be recognizable not only by performers themselves . . . but also by most listeners. ${ }^{83}$

Zhou and Fabian nevertheless speak quite broadly of 'individual differences' as 'the variance between people on the one hand - that is, how people are different-and the central tendency of a person on the other-that is, how a person can best be described in terms of an overall within-person average'. ${ }^{84}$ What all this means is that the basic definition of individuality is exclusively wrapped up in auditory parameters, and it is suggested that these parameters are the means by which 'performers are distinguished and valued'. This allows them to develop a three-dimensional model 'whereby six variables' - all pertaining to tempo, though they suggest that this could be widened to other auditory parameters - 'can be measured, assessed, and combined so that individual differences both among performances as well as among performers can be evaluated'.

The point is not so much that there is anything methodologically faulty or inconsistent about this approach; it is more a question of whether or not defining a performer's individuality without reference to their life is sensible. What might we be losing by gathering data and comparing performance styles in a way that resembles a kind of performance-analytical equivalent of studying the 'music itself? Indeed, the complete absence from this discussion of 'extra-musical' features (the importance of which, when framed in these terms, is certainly undermined) and the assertion that we 'should also have a more scientific, evidence-based way of describing the individual artistry of specific performers' leads me to wonder whether this kind of approach is more committed to its own methodology than it is to its purported object of study. ${ }^{85}$ I do not mean to suggest that such work is without value; on the contrary, that is why I have dedicated so much space to discussing it. In this respect, it is important that Fabian's goal is quite specific. Her interest in the evolution of performance styles points towards a broader history of style as the ultimate goal, a kind of history in which 'personal styles' could be related to each other and made sense of within a 'period style' (to use Leech-Wilkinson's terms), all of which could be determined or at least informed by the use of data extracted from sound recordings. ${ }^{86}$

I said that I would return to the question of context. Fabian's goal involves a very specific orientation of context; in this instance, the historical context refers to the sound world at play for any given recording, how one performer's 'expressive gestures' (to use Leech-Wilkinson's term) might relate to others during the same period, for instance. This kind of sound context is quite different from the one that Leech-Wilkinson gives us in his example of Cortot in Vichy France, that is, that Cortot's personal life, his public engagement, and wider factors

83 Danny Quan Zhou and Dorottya Fabian, 'A Three-Dimensional Model for Evaluating Individual Differences in Tempo and Tempo Variation in Musical Performance', Musicae Scientiae (2019), 2.

84 Zhou and Fabian, 'Three-Dimensional Model', 2-3.

85 Zhou and Fabian, 'Three-Dimensional Model', 12.

86

As we saw, Leech-Wilkinson had a similar vision. 
178 Behan The Historiography of the Twentieth-Century Classical Performer: Life, Work, Artistry

of his cultural and social surroundings might tell us something about his playing. It is similarly different from Bazzana's construction of the Gould 'aesthetic'. A more elaborate example in this vein would have much less to do with style comparison than with thick cultural description, and it is in this sense that it also has more to do with Cook's all-encompassing understanding of music as performance. Alternatively, when Sarlo speaks of his own 'new method' that will ensure 'performances can be assessed in historical and interpretative context' - more particularly, when he claims that his study of Heifetz's performances of Bach Preludes in their 'historical and interpretative context will reveal both what he shares with other musicians, and what is distinct, or unique to him' - it is the sound world context that he has in mind. ${ }^{87}$ It is also what Zhou means when he speaks of the performance 'norm' as a situating context, that 'to study individual differences in performance style is to study whether a performer plays more similarly to him/herself over time and across repertoire than he/she does to others, and whether the variation within the performances of a particular performer over time and across repertoire is less than that between performers in general'. ${ }^{88}$

Perhaps the most charitable way to characterize this state of affairs, then, is to say that different scholars have different kinds of context in mind. As with Kerman's diagnosis of positivism before, there are resonances here with the cleavage that Philip Auslander has identified between musicology and performance studies: he writes that musicology is 'the discipline that explicates music per se [by which he means "the music itself"], while performance studies is the discipline that can tell us about the social meanings music generates in performance, ${ }^{89}$ This, in many ways, captures how biographers and musicologists have written about the individual performer, too. But while the sound world context might suffice for metanarratives of performance style throughout the twentieth and twenty-first centuries - the kind that Fabian has in mind when she speaks of mainstream and historically informed performance (HIP) styles - an account of individual performers (and a definition of individuality) that fails to go beyond this serves only to dehumanize the musical performances that such metanarratives are built upon. The kind of biographical contexts highlighted in the previous section go some way to supporting just how much there is to lose. To argue for the centralization of these contexts is effectively to take Cook's broader point about the need to view recordings as 'the traces of human actions in specific social and cultural situations' and to apply it more narrowly to the literature on the individual performer. ${ }^{90}$ More immediately, however, I have tried to show something of the slippery slope down which empirical approaches to recordings have slid since CHARM: although initially conceptualized by Leech-Wilkinson in terms of performance style awaiting further contextualization, auditory parameters - the sound of music

87 Sarlo, Jascha Heifetz, 5.

88 Danny Quan Zhou, 'Evaluating Individual Differences in Musical Performance Style: An Empirical Study of Tempo and Timing Variation in Contemporary Recorded Performances of the Solo Piano Music of Chopin and Liszt' (PhD diss., University of New South Wales, 2018), 59-60.

89 Philip Auslander, 'Afterword. Music as Performance: The Disciplinary Dilemma Revisited', in Taking it to the Bridge: Music as Performance, ed. Richard Pettengill and Nicholas Cook (Ann Arbor: University of Michigan Press, 2013), 352.

90 Cook, 'Bridging the Unbridgeable', 76. 
- have since come to define musical expressiveness first of all, and more recently have been used to define not just performance but the very notion of musical individuality. Towards the conclusion of his 1982 article, Solomon pithily summarized a state of affairs which mirrors the present discussion: '[a]rt achieves a virgin birth: life is thrown overboard'. ${ }^{91}$

\section{Leads from elsewhere}

Earlier, I paraphrased Cook's call in 2013 to bridge the gap between interdisciplinary performance studies and empirical approaches to recordings. I hope to have made clear that an analogous gap exists between the latter and biographical approaches to studying individual performers, but that it is one with a long legacy and in which a sharp divide between the 'musical' and the 'extra-musical' has effectively been disciplinarily consolidated. Even with the advent of sophisticated tools for analysing recordings, the practice of performer biography remains committed to its traditional methods of historical research - no doubt in part due to its ostracization from the 'musicological arena', as Wiley and Watt put it. Empirical approaches to recordings have increasingly exhibited a tendency to bypass the kind of contextually grounded explanations of performer individuality typical of biographies in favour of the purely aural dimensions of what performers do. None of this is to say that valuable insights cannot be gained from these kinds of studies in isolation, but to break down the scholarly boundaries between these two categories and to synergize their various approaches could offer us new prospects for the historical study of performers.

There are many directions in which we could run with this, and I would like briefly to consider two by way of concluding this article. The first draws not on the work of a historian or a musicologist (in the traditional sense), but on that of a performer - or, more specifically, an artistic researcher. Space prevents a detailed discussion of artistic research here; put simply, it is a form of practice-led research that is guided by artistic goals. For artistic researchers, the tacit, embodied, and experiential knowledge to which performers have access is crucial to understanding music but which has been routinely stifled in musicology because the entire discipline 'was set up around the idea of music as writing rather than music as performance'. 92 Those are in fact Cook's words - that is, those of a musicologist rather than a performer - but for some practice-led researchers it seems more attractive to carve out their own intellectual space instead of slowly recuperating a form of music studies that has been set up to exclude them. $^{93}$

91 Solomon, 'Thoughts on Biography', 276.

92 Cook, Beyond the Score, 1.

93 For some of the most trenchant critiques of musicology and performance studies - some of them more nuanced than others - see: John Rink, 'The State of Play in Performance Studies', in The Music Practitioner: Research for the Music Performer, Teacher and Listener, ed. Jane W. Davidson (Aldershot: Ashgate, 2004); Mine Doğantan-Dack, 'Recording the Performer's Voice', in Recorded Music: Philosophical and Critical Reflections, ed. Mine Doğantan-Dack (London: Middlesex University Press, 2008), 294; Mine Doğantan-Dack, 'Practice-as-research in Music Performance', in The Sage Handbook of Digital Dissertations and Theses, ed. Richard Andrews, Stephen Boyd-David, Myrrh Domingo, Jude England, and Erik Borg (London: Sage, 2012), 263; Jonathan Impett, 'Introduction', in Artistic Research in Music: Discipline and Resistance, ed. Jonathan Impett (Leuven: Leuven University Press, 2017), 9; Paulo de Assis, 
180 Behan The Historiography of the Twentieth-Century Classical Performer: Life, Work, Artistry

In an essay from 2008, Mine Doğantan-Dack attempted to map a kind of 'pianistic phenomenology', which she explored in the second movement of Beethoven's Piano Sonata No. 8 in C minor, Op. 13 ('Pathétique'). ${ }^{94}$ Her point of departure was the physical constraint placed on the performer's hand when playing the main theme. She writes that the wrist is not 'free to "breathe" as in normative pianistic cantabile practice' (the score is marked Adagio cantabile). But with the arrival of the fourth and fifth iterations of the main theme, the physical distribution of the musical texture changes and 'the accompaniment, now in triplets, allows the "singing" fingers playing the melody more elasticity', the experience of which resembles 'a progression from restraint to more freedom to sing'. What matters is how the performer integrates this feature into a specific interpretation and with what aesthetic convictions: 'should the relative pianistic freedom gained by the melody in bar 51 of the second movement of the Pathétique be interpreted as a goal, and expressed through the creation of a sense of direction towards bar 51', asks Doğantan-Dack, 'or should it be understood more as an event that just comes to pass?'

Doğantan-Dack chooses the first option over the second, but I am interested less in this choice than in the basic point that she is indirectly making about artistic decision-making. She defers to the interpretations of Artur Schnabel - asking what his 'aesthetic assumptions' were 'when he introduced long drawn-out lines, and waves of dynamic changes' in his 1934 performance - and Claudio Arrau, likewise wondering what 'aesthetic preferences' drove him 'to create a quasi stasis, a feeling of labouring' with his exceptionally slow tempo in his 1963 recording. All of this is to say that pianistic choices relate in some way to a form of aesthetic thinking; in other words, that the performer's manipulation of tempo, dynamics, and other auditory parameters might make up the musical fingerprints of a wider artistic idea or vision. Doğantan-Dack's own decision might best be understood in terms of narrativity given her conceptualization of bar 51 as a figurative destination, but other decisions could well be explored more usefully in programmatic thinking. ${ }^{95}$ An example of the latter might be Neuhaus's cypresses in Bach's prelude and fugue that was considered earlier. Although the idea was only expressed much later by Doğantan-Dack, her notion of a 'personal artistic voice' - what she calls 'the highest aspiration for any performer who desires to express and communicate an artistic experience, understanding, vision or truth through music-making' - is more or less an elaboration of her idea of 'aesthetic preferences'. ${ }^{96}$

'Introduction', in Virtual Works - Actual Things: Essays in Music Ontology, ed. Paulo de Assis (Leuven: Leuven University Press, 2018), 17; Paulo de Assis, Logic of Experimentation: Reshaping Music Performance in and through Artistic Research (Leuven: Leuven University Press, 2018), 13; Lucia D’Errico, Powers of Divergence: An Experimental Approach to Music Performance (Leuven: Leuven University Press, 2018), 14.

94 Doğantan-Dack, 'Recording the Performer's Voice', 306-8.

95 A case for bringing concepts of narrativity more fully into performance studies is made by John Rink in 'The Work of the Performer', in Virtual Works - Actual Things: Essays in Music Ontology, ed. Paulo de Assis (Leuven: Leuven University Press, 2018), 89-114.

96 Mine Doğantan-Dack, 'Expressive Freedom in Classical Performance: Insights from a Pianist-Researcher', in Musicians in the Making: Pathways to Creative Performance, ed. John Rink, Helena Gaunt, and Aaron Williamon (Oxford: Oxford University Press, 2017), 131. This is a sentiment that is echoed by many other emerging performerresearchers including (the following are all from Musicians in the Making: Pathways to Creative Performance, ed. John 
By focusing on classical musicians I have so far avoided engaging with popular music studies, which is where, as Georgina Born notes, 'the origins of academic research on recording and music media lie'. 97 The fact that, for popular musics of many kinds, 'the recorded musical text is the primary text' meant that recordings were never going to be treated as an optional extra to the field of popular music studies in the way in which they arguably have been for so long for biographical studies of classical performers. Born writes that ' $[\mathrm{i}] \mathrm{n}$ most genres of twentieth-century popular music, musical interest resides not so much in harmonic, melodic or formal complexity or development, as it does in Western art music, but in timbral and rhythmic nuance and subtlety within fairly fixed and repetitive structures', and it is in fact in relation to timbre that Nina Sun Eidsheim undertakes her analysis of the jazz singer Jimmy Scott. ${ }^{98}$ Scott was born with Kallman syndrome, a hormonal condition that prevented his voice from changing at puberty, meaning that it remained throughout his life higher in tessitura than that of a man who had gone through the hormonally induced vocal changes that typically take place during puberty' (a classical music parallel to the resulting sound is the castrato). ${ }^{99}$

Scott worked in relative obscurity for most of his career, achieving celebrity status only in later years, and Eidsheim pinpoints the reason for this as the incommensurability of Scott's artistry with the hypermasculinity that came to be associated with contemporary jazz figures such as Miles Davis and John Coltrane, what Eidsheim calls a 'culturally and historically situated idea of the African American male jazz artist'. ${ }^{100}$ Crucially, this incommensurability shaped how his music was imagined more broadly from an early stage and was engineered and perpetuated by record labels who, for instance, effaced his identity from some of his records (his 1969 album The Source tellingly features a female model on the cover instead of Scott). Yet it was also prompted by the timbre of his voice. ${ }^{101}$ A particular timbral quality that characterized this contemporary hypermasculinity was falsetto, a registral shift that was missing from Scott's smoothly connected vocal range. Eidsheim writes that 'Scott was othered not because of his higher voice, but because of his consistent timbre, evidencing his inability or unwillingness to delineate a so-called real masculine vocal range from its so-called false upper extension'. ${ }^{102}$ The point is that Eidsheim's account benefits from the interaction of her close analysis of the specifically sonic qualities of Scott's singing with the attention she pays to the biography, reception and context of Scott the cultural figure.

Rink, Helena Gaunt, and Aaron Williamon (Oxford: Oxford University Press, 2017)) Jane Manning, 'The Creative Voice in Artistic Performance'; Carlos Lopez-Real, 'Musical Artistry and Identity in Balance'; Helen Reid, 'Making Connections'; and Frances-Marie Uitti, 'Beyond Convention: Listening to One's Inner Voice'.

97 Georgina Born, 'Recording: From Reproduction to Representation to Remediation', in The Cambridge Companion to Recorded Music, ed. Nicholas Cook, Eric Clarke, Daniel-Leech-Wilkinson, and John Rink (Cambridge: Cambridge University Press, 2009), 290.

98 Born, 'Recording: From Reproduction to Representation to Remediation', 296.

99 Nina Sun Eidsheim, The Race of Sound: Listening, Timbre, and Vocality in African American Music (Durham: Duke University Press, 2018), 93.

100 Eidsheim, The Race of Sound, 92, 101.

101 Eidsheim, The Race of Sound, 97-8.

102 Eidsheim, The Race of Sound, 109-10. 
The examples of Doğantan-Dack and Eidsheim are simply two directions forward. My general point is more to do with the seemingly entrenched separation of different approaches to and perspectives on what we might broadly call a musician's artistry - approaches which could very well be deployed together or brought into dialogue. Allusions to artistry might seem to carry us to much more elusive and ineffable territory, but what is so conceptually useful about Doğantan-Dack's notion of an 'artistic voice' is that it encompasses the element of performance style that empirical approaches can illuminate as well as the sense of individuality that both goes beyond an empirical understanding of 'style' and is contextually supplemented by a musician's aesthetic thinking or outlook, biographical circumstance, or possibly in some other way. This notion is flexible enough to capture the features of cultural and social context supplied by historical methods - the kind that biographers have long used - while also potentially embracing the use of empirical approaches, which themselves facilitate the discussion of the performer's 'work' in a particularly rigorous and exchangeable way. More simply, it helps to solve the problem of the 'extra-musical' that has cropped up consistently in this article. Cook suggested that there should be no distinction between the musical and the extramusical when it comes to performance; the argument I am making is that this is true of the performer's artistry, too - however we choose to construct it.

\section{Bibliography}

Assis, Paulo de. Logic of Experimentation: Reshaping Music Performance in and through Artistic Research. Leuven: Leuven University Press, 2018.

—, ed. Virtual Works - Actual Things: Essays in Music Ontology. Leuven: Leuven University Press, 2018.

Auslander, Philip. 'Afterword. Music as Performance: The Disciplinary Dilemma Revisited', in Taking It to the Bridge: Music as Performance, ed. Richard Pettengill and Nicholas Cook. Ann Arbor: University of Michigan Press, 2013. 349-57.

Barolsky, Daniel. 'Performers and Performances as Music History: Moving Away from the Margins', in Norton Guide to Teaching Music History, ed. C. Matthew Balensuela. New York: Norton, 2019. 159-71.

Bazzana, Kevin. Glenn Gould: The Performer in the Work. Oxford: Clarendon Press, 1997.

- Wondrous Strange: The Life and Art of Glenn Gould. New Haven, CT: Yale University Press, 2004.

Beauclerk, Charles. Piano Man: A Life of John Ogdon. London: Simon \& Schuster, 2014.

Born, Georgina. 'Recording: From Reproduction to Representation to Remediation', in The Cambridge Companion to Recorded Music, ed. Nicholas Cook, Eric Clarke, Daniel Leech-Wilkinson, and John Rink, Cambridge: Cambridge University Press, 2009. 286-304.

Collingwood, R. G. The Idea of History. Oxford: Clarendon Press, 1946.

Cone, Edward T. Musical Form and Musical Performance. New York: Norton, 1968.

Cook, Nicholas. Beyond the Score: Music as Performance. Oxford: Oxford University Press, 2013.

. 'Bridging the Unbridgeable? Empirical Musicology and Interdisciplinary Performance Studies', in Taking It to the Bridge: Music as Performance, ed. Richard Pettengill and Nicholas Cook. Ann Arbor: University of Michigan Press, 2013. 70-85.

—. 'The Ghost in the Machine: Towards a Musicology of Recordings'. Musicae Scientiae 14/2 (2010), 3-21.

. 'Implications for Music Studies', in Expressiveness in Music Performance: Empirical Approaches across Styles and Cultures, ed. Dorottya Fabian, Renee Timmers, and Emery Schubert. Oxford: Oxford University Press, 2014. 331-4. 3-24.

D’Errico, Lucia. Powers of Divergence: An Experimental Approach to Music Performance. Leuven: Leuven University Press, 2018.

Doğantan-Dack, Mine. 'Expressive Freedom in Classical Performance: Insights from a Pianist-Researcher', in Musicians in the Making: Pathways to Creative Musical Performance, ed. John Rink, Helena Gaunt, and Aaron Williamon. Oxford: Oxford University Press, 2017. 131-5. 
'Philosophical Reflections on Expressive Music Performance', in Expressiveness in Music Performance: Empirical Approaches across Styles and Cultures, ed. Dorottya Fabian, Renee Timmers, and Emery Schubert. Oxford: Oxford University Press, 2014. 3-21.

- 'Practice-as-Research in Music Performance', in The Sage Handbook of Digital Dissertations and Theses, ed. Richard Andrews, Stephen Boyd-Davies, Myrrh Domingo, Jude England, and Erik Borg. London: Sage, 2012. 259-75.

- 'Recording the Performer's Voice', in Recorded Music: Philosophical and Critical Reflections, ed. Mine Doğantan-Dack. London: Middlesex University Press, 2008. 292-313.

Eidsheim, Nina Sun. The Race of Sound: Listening, Timbre, and Vocality in African American Music. Durham: Duke University Press, 2018.

Fabian, Dorottya. A Musicology of Performance: Theory and Method Based on Bach's Solos for Violin. Cambridge: Open Book Publishers, 2015.

Fabian, Dorottya, and Eitan Ornoy. 'Identity in Violin Playing on Records: Interpretation Profiles in Recordings of Solo Bach by Early Twentieth-Century Violinists'. Performance Practice Review 14/1 (2009), 1-40.

Fabian, Dorrotya, Renee Timmers, and Emery Schubert, eds. Expressiveness in Music Performance: Empirical Approaches across Styles and Cultures. Oxford: Oxford University Press, 2014.

Impett, Jonathan, ed. Artistic Research in Music: Discipline and Resistance. Leuven: Leuven University Press, 2017. Isacoff, Stuart. When the World Stopped to Listen: Van Cliburn's Cold War Triumph, and Its Aftermath. New York: Knopf, 2017.

Kerman, Joseph. 'How We Got into Analysis, and How to Get Out'. Critical Inquiry 7/2 (1980), 311-31.

- Musicology. London: Fontana Press/Collins, 1985.

Leech-Wilkinson, Daniel. The Changing Sound of Music: Approaches to Studying Recorded Musical Performances. London: CHARM, 2009. www.charm.rhul.ac.uk/studies/chapters/intro.html (accessed 12 June 2020).

- 'Making Music with Alfred Cortot: Ontology, Data, Analysis', in Gemessene Interpretation Computergestützte Aufführungsanalyse Im Kreuzverhör Der Disziplinen, ed. Heinz Loesch and Stefan Weinzierl. Mainz: Schott, 2011. 129-44.

_. 'Performance Style in Elena Gerhardt's Schubert Song Recordings'. Musicae Scientiae 14/2 (2010), 57-84.

- 'Recordings and Histories of Performance Style', in The Cambridge Companion to Recorded Music, ed. Nicholas Cook, Eric Clarke, Daniel Leech-Wilkinson, and John Rink. Cambridge: Cambridge University Press, 2009. 246-62.

- 'Sound and Meaning in Recordings of Schubert's "Die Junge Nonne". Musicae Scientiae 11/2 (2007), 209-36.

Lehmann, Stephen, and Marion Faber. Rudolf Serkin: A Life. Oxford: Oxford University Press, 2003.

Lopez-Real, Carlos. 'Musical Artistry and Identity in Balance', in Musicians in the Making: Pathways to Creative Performance, ed. John Rink, Helena Gaunt, and Aaron Williamon. Oxford: Oxford University Press, 2017. 241-4.

Manning, Jane. 'The Creative Voice in Artistic Performance', in Musicians in the Making: Pathways to Creative Performance, ed. John Rink, Helena Gaunt, and Aaron Williamon. Oxford: Oxford University Press, 2017. 126-30.

McKenna, Marian C. Myra Hess: A Portrait. London: Hamilton, 1976.

Nicholas, Jeremy. Godowsky, The Pianists' Pianist: A Biography of Leopold Godowsky. Hexham: Appian Publications \& Recordings, 1989.

Pekacz, Jolanta T., 'Musical Biography - Further Thoughts', in Music's Intellectual History: Founders, Followers \& Fads, ed. Zdravko Blažeković and Barbara Dobbs MacKenzie. New York: RILM, 2009. 843-52.

- ed. Musical Biography: Towards New Paradigms. Aldershot: Ashgate, 2006.

Philip, Robert. Early Recordings and Musical Style: Changing Tastes in Instrumental Performance, 1900-1950. Cambridge: Cambridge University Press, 1992.

Razumovskaya, Maria. Heinrich Neuhaus: A Life Beyond Music. La Vergne: Boydell \& Brewer, 2018.

Reid, Helen. 'Making Connections', in Musicians in the Making: Pathways to Creative Performance, ed. John Rink, Helena Gaunt, and Aaron Williamon. Oxford: Oxford University Press, 2017. 248-50.

Rink, John. 'The (F)utility of Performance Analysis', in Artistic Practice as Research in Music, ed. Mine Doğantan-Dack. Farnham: Ashgate, 2015. 127-48.

. 'Review of Musical Structure and Performance by Wallace Berry'. Music Analysis 9/3 (1990), 319-39.

. 'The State of Play in Performance Studies', in The Music Practitioner: Research for the Music Performer, Teacher and Listener, ed. Jane W. Davidson. Aldershot: Ashgate, 2004. 37-52.

. 'The Work of the Performer', in Virtual Works - Actual Things: Essays in Music Ontology, ed. Paulo de Assis. Leuven: Leuven University Press, 2018. 89-114. 
Rink, John, Neta Spiro, and Nicolas Gold. 'Motive, Gesture and the Analysis of Performance', in New Perspectives on Music and Gesture, ed. Anthony Gritten and Elaine King. Farnham: Ashgate, 2011. 267-92.

Sachs, Harvey. Arthur Rubinstein: A Life. London: Weidenfeld \& Nicolson, 1996.

Sarlo, Dario. The Performance Style of Jascha Heifetz. Farnham: Ashgate, 2015.

Schonberg, Harold C. Horowitz: His Life and Music. New York: Simon \& Schuster, 1992.

Solomon, Maynard. 'Biography', in The New Grove Dictionary of Music and Musicians, 2nd edn, ed. Stanley Sadie and John Tyrrell. London: Macmillan, 2001. Version at Grove Music Online, ed. Larua Macy. www.oxfordmusiconline.com/grovemusic/view/10.1093/gmo/9781561592630.001.0001/omo-9781561592630-e-0000041156? rskey=0AYRHt (accessed 12 June 2020).

_. 'Thoughts on Biography'. 19th-Century Music 5/3 (1982), 268-76.

Uitti, Frances-Marie. 'Beyond Convention: Listening to One's Inner Voice', in Musicians in the Making: Pathways to Creative Performance, ed. John Rink, Helena Gaunt, and Aaron Williamon. Oxford: Oxford University Press, 2017. 344-6.

Wiley, Christopher. 'Biography and Life-Writing', in The Oxford Handbook of Music and Intellectual Culture in the Nineteenth Century, ed. Paul Watt, Sarah Collins, and Michael Allis. Oxford: Oxford University Press, 2020.

Wiley, Christopher, and Paul Watt. 'Musical Biography in the Musicological Arena'. Journal of Musicological Research 38/3-4 (2019). 187-92.

—, eds. 'Musical Biography: Myth, Ideology, and Narrative'. Journal of Musicological Research 38/3-4 (2019). 187-361.

Zhou, Danny Quan. 'Evaluating Individual Differences in Musical Performance Style: An Empirical Study of Tempo and Timing Variation in Contemporary Recorded Performances of the Solo Piano Music of Chopin and Liszt'. PhD diss., University of New South Wales, 2018.

Zhou, Danny Quan, and Dorottya Fabian. 'A Three-Dimensional Model for Evaluating Individual Differences in Tempo and Tempo Variation in Musical Performance’. Musicae Scientiae (2019), 1-16. 